\title{
Supero-nasal Subluxation of Lens in Homocystinuria - A Rare Case Report
}

\author{
Dr.Shashank Shekhar ${ }^{1}$, Dr.Dipti Neha ${ }^{2}$, Dr.M.R.Akhouri ${ }^{3}$ \\ ${ }^{1}$ Junior Resident, ${ }^{2}$ Junior Resident, ${ }^{3}$ Associate Professor \\ Department of Pediatrics and Neonatology, RIMS, Ranchi, Jharkhand
}

\section{Introduction}

Homocystinuria is a rare congenital disorder having autosomal recessive inheritance. It is most commonly caused by deficiency of cystathione beta synthase (CBS) enzyme which catalyses the synthesis cystathione from homocysteine and serine in the methionine pathway. This results in accumulation of homocysteine and methionine in plasma and leads to excretion of excessive urinary homocysteine ${ }^{1}$. The gene for CBS is located on chromosome 21q22.3. The screening of newborn infants for classical homocystinuria has been performed worldwide with a prevalence of 1 in 200000 to 1 in 350000 live births. Approximately $40 \%$ of the affected patients respond to high doses of Vit. $\mathrm{B}^{2}$. Pyridoxine responsiveness is based on small residual activity of CBS which is not present in patients unresponsive to Vit. B6 therapy. It is characterised by multi system disorders including ectopia lentis (infero nasal subluxation of lens), intellectual disability, psychiatric and behavioural disorders, skeletal abnormalities along with thromboembolic episodes. ${ }^{3}$

This case study describes a rare case of homocystinuria in a $7 \mathrm{yrs}$ old male child with superonasal subluxation of lens in right eye and dislocated lens in the anterior chamber of left eye along with other clinical manifestations.

Key Words: Cystathione beta synthase, Vit.B6 responsiveness, Superonasal lens subluxation

\section{Case Report}

A 7yrs old male child reported to Department of Paediatrics and Neonatology, RIMS, Ranchi with complaints of headache, vomiting, irritability, delirium and watering from both eyes . Patient is the third child of healthy parents of non consanguineous marriage.

Detailed history revealed repeated episodes of headache for the last 2 years. Antenatal, natal and neonatal history were non contributory with no significant family history. On general examination weight $18 \mathrm{~kg}$, height $-115 \mathrm{~cm}$, arm span $-118 \mathrm{~cm}$, upper segment $-51 \mathrm{~cm}$, lower segment $-64 \mathrm{~cm}$ with a ration of $0.8: 1$, pectus carinatum, high arched palate, crowding of teeth, ataxic gait with motor incoordination and diminished vision. Ocular examination revealed superonasally subluxated lens in right eye and dislocated lens in anterior chamber in left eye, iridodonesis along with vitreous degeneration in both the eyes. IQ of the patient was 43.

Biochemical tests such as urine nitroprusside test was positive suggesting homocystinuria. The serum homocysteine level was $140.99 \mu \mathrm{mol} / \mathrm{l}$ (normal range $=5.46-16.20 \mu \mathrm{mol} / \mathrm{l}$ ). His fasting plasma methionine level was $126.12 \mu \mathrm{mol} / \mathrm{l}$ (normal range $=0-90 \mu \mathrm{mol} / \mathrm{l})$. The thyroid profile and blood counts were within normal limits. Other investigations like EEG and CECT brain did not reveal any organic brain lesion.

Based on these investigations and clinical findings we made the diagnosis of homocystinuria type-1 and the patient was started on oral Vit.B6 (pyridoxine) $400 \mathrm{mg} /$ day and folic acid 5mg/day. The child responded well to this therapy with improvement in neuropsychiatric manifestations. Later he was referred to Department of Ophthalmology where an intracapsular crystalline lens extraction was performed. After the lens extraction, an iris-fixated IOL was implanted. 


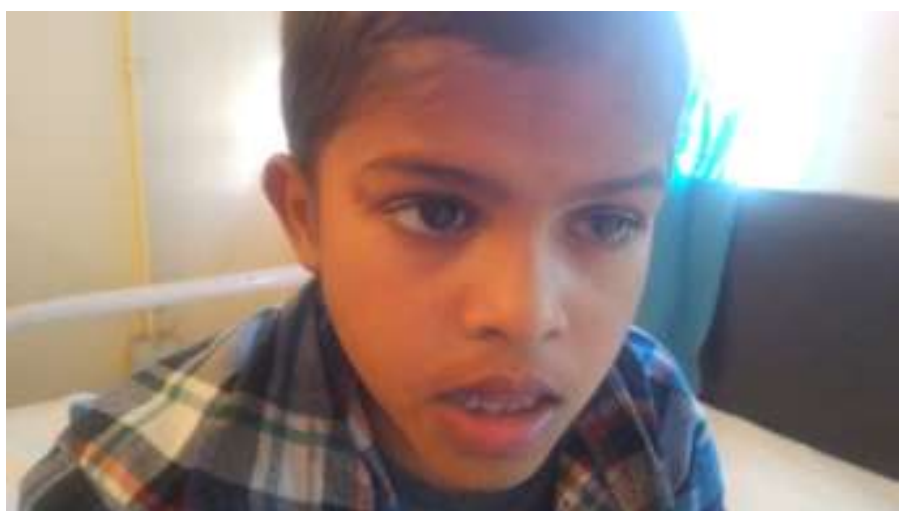

Fig. 1 showing watering of eyes

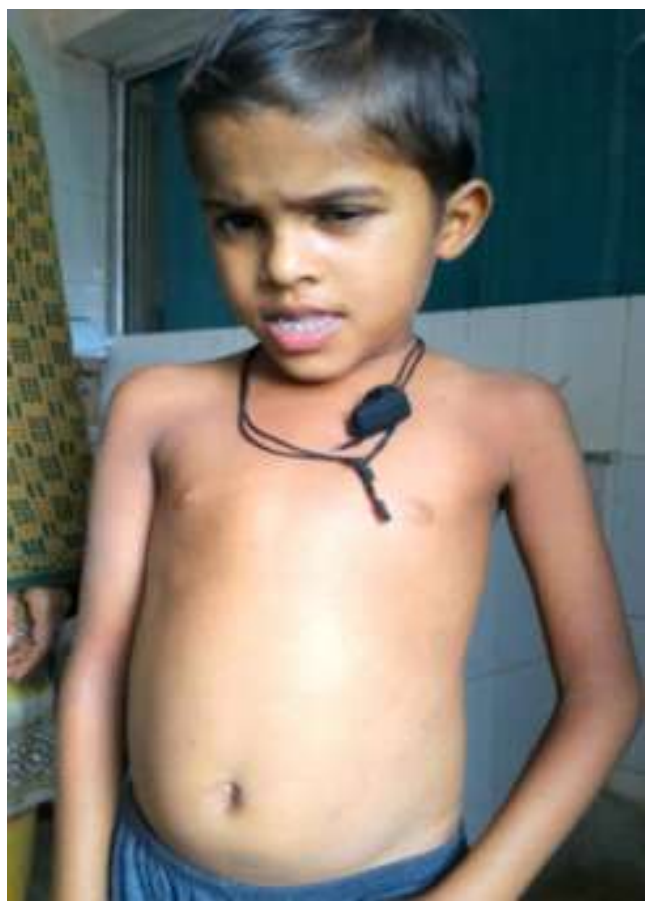

Fig.2 showing pectus carinatum

\section{Discussion}

Differential diagnosis of homocystinuria includes Marfan syndrome and sulphite oxidase deficiency. Individuals with these disorders have normal concentrations of plasma homocysteine and methionine level. Homocystinuria is the most common inborn error of methionine metabolism. It occurs most commonly due to deficiency of CBS enzyme. Less common causes of homocystinuria are deficiency of 5, 10-methylene tetrahydrofolate reductase and defects in methyl cobalamine formation ${ }^{4}$. 


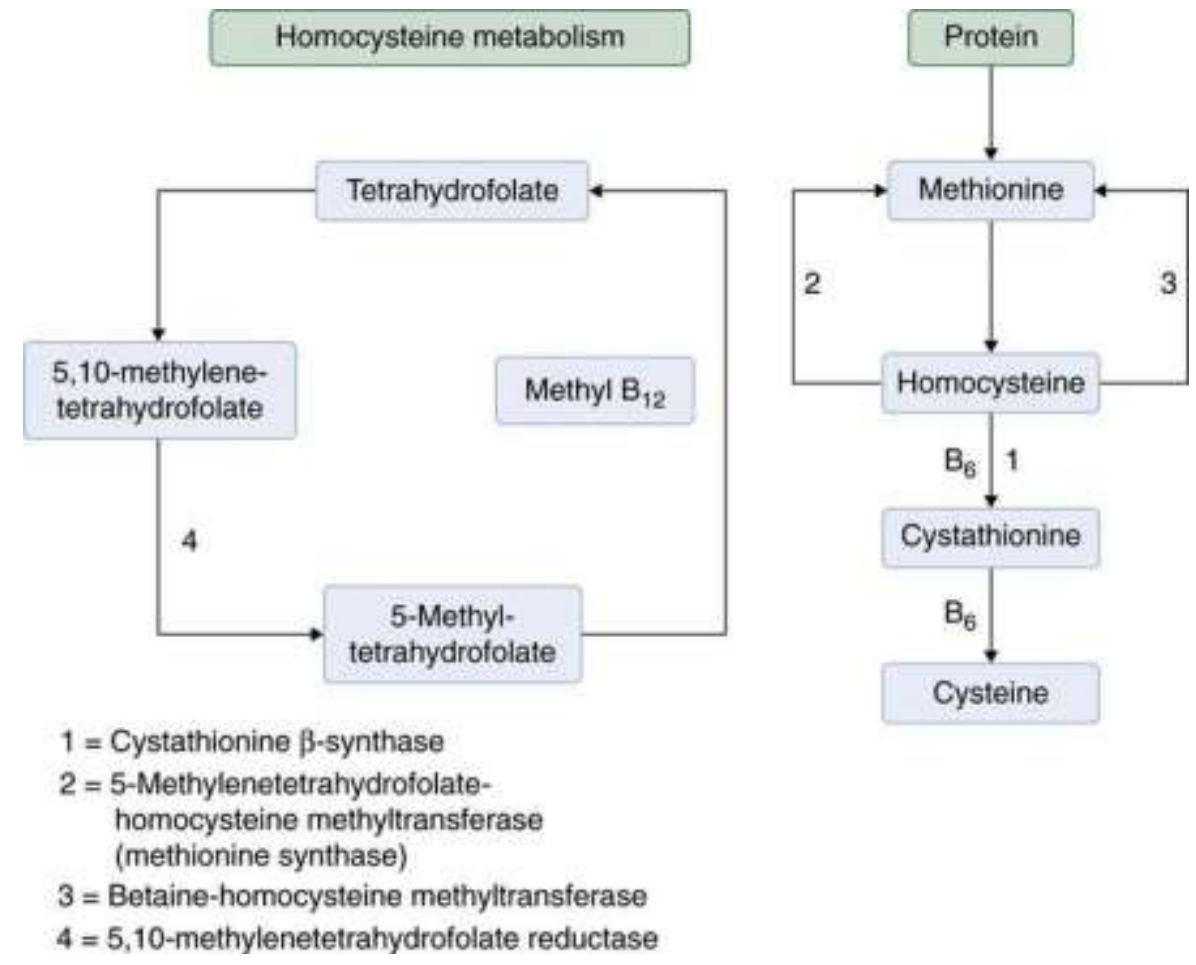

Infants with this disorder are normal at birth. Clinical manifestations during infancy are non specific and may include failure to thrive and developmental delay. The major clinical manifestations include ocular manifestations (ectopia lentis, severe myopia, iridodonesis, astigmatism, glaucoma, staphyloma, cataract, retinal detachment, vitreous degeneration, optic atrophy), progressive intellectual disability, psychiatric and behavioural disorders, convulsions, skeletal abnormalities (scoliosis, pectus carinatum, pectus excavatum, genu valgum, pes cavus, high arched palate, crowding of teeth) and thromboembolic episodes involving both large and small vessels ${ }^{1}$.

On the basis of treatment, two types of homocystinuria have been reported: one is Vit.B6 responsive and the other is Vit.B6 unresponsive. Treatment of Vit.B6 responsive patients include high dose of Vit.B6 (200$1000 \mathrm{mg} / 24 \mathrm{hrs})$ along with folic acid $(1-5 \mathrm{mg} / 24 \mathrm{hrs})$ which significantly reduces homocysteine levels 5 . Treatment of Vit.B6 unresponsive patients include dietary restriction of methionine intake in conjugation with cysteine supplementation along with betaine therapy $(200-250 \mathrm{mg} / \mathrm{kg} / 24 \mathrm{hrs})$. The principle of the treatment is to correct biochemical abnormalities mainly to control the elevated level of plasma homocysteine and to prevent the complications. Prenatal diagnosis is made by performing enzyme assay of cultured amniotic cells or chorionic vilii or by DNA analysis. These cases show best results when treated shortly after birth with a goal to maintain plasma homocysteine concentration less than $11 \mu \mathrm{mol} / 1 .^{6}$

It is noteworthy that only a few cases of homocystinuria have been reported from India, none of these has been associated with superonasal subluxation of lens as seen in our case.

\section{References}

[1]. Mudd SH, Skovby F, Levy HL, Pettigrew KD, Wilken B, Pyeritz RE, et al. The natural history of homocystinuria due to cystathionine beta-synthase deficiency. Am J Hum Genet 1985; 37:1-31

[2]. Iraj Rezwani and David S. Rosenblatt, Methionine: Metabolic disorders, Nelson textbook of Pediatrics, 20th International Edition 2015, Volume 1; 85: pg 644

[3]. Rao TN, Radhakrishna K, Rao TSM et al Homocystinuria due to cystathionine beta synthase deficiency. Indian J Dermatol Venereol Leprol 2008; 74:375-8

[4]. Skovby F, Gaustadnes M, Mudd SH: A revisit to the natural history of homocystinuria due to cystathionine beta-synthase deficiency, Mol Genet Metab 99:1-3, 2010

[5]. Picker JD, Levy HL: Homocystinuria caused by cystathionine beta-synthase deficiency. January 15, 2004 [Updated April 26, 2011]. In Pagon RA, Adam MP, Ardinger HH, et al, editors: GeneReviews [Internet], Seattle (WA), 1993-2014, University of Washington, Seattle.

[6]. Fowler B, Jakobs C. Post- and prenatal diagnostic methods for the homocystinurias. Eur J Pediatr. 1998;157Suppl 2:S88-93 